NBER WORKING PAPER SERIES

\title{
SHORT RUN CONSTRAINTS AND THE INCREASING MARGINAL VALUE OF TIME IN RECREATION
}

Raymond B. Palmquist

Daniel J. Phaneuf

V. Kerry Smith

Working Paper 14986

http://www.nber.org/papers/w14986

\author{
NATIONAL BUREAU OF ECONOMIC RESEARCH \\ 1050 Massachusetts Avenue \\ Cambridge, MA 02138
}

May 2009

Partial support for this research was provided by the U.S. Environmental Protection Agency under grant no. R-82950801 and by CEnREP at North Carolina State University. Thanks are due Doug Larson and two anaonymous referees for very helpful comments on an earlier draft, to Jaren Pope and Brian Stynes for their assistance in conducting the survey used for this analysis, and to Melissa Brandt, Michael Darden, Eric McMillen and Vincent McKeever for assistance in assembling the data from the household survey. The views expressed herein are those of the author(s) and do not necessarily reflect the views of the National Bureau of Economic Research.

NBER working papers are circulated for discussion and comment purposes. They have not been peerreviewed or been subject to the review by the NBER Board of Directors that accompanies official NBER publications.

(C) 2009 by Raymond B. Palmquist, Daniel J. Phaneuf, and V. Kerry Smith. All rights reserved. Short sections of text, not to exceed two paragraphs, may be quoted without explicit permission provided that full credit, including $(\mathcal{O}$ notice, is given to the source. 
Short Run Constraints and the İncreasing Marginal Value of Time in Recreation

Raymond B. Palmquist, Daniel J. Phaneuf, and V. Kerry Smith

NBER Working Paper No. 14986

May 2009

JEL No. D13,J22,Q26

\begin{abstract}
$\underline{\text { ABSTRACT }}$
Leisure activities such as local recreation trips usually take place in discrete blocks of time that are surrounded by time devoted to other commitments. It can be costly to transfer time between blocks to allow for longer outings. These observations affect the value of time within those blocks and suggest that traditional methods for valuing time using labor markets miss important considerations. This paper presents a new model for time valuation that uses non-employment time commitments to infer the shadow value of time spent in recreation. A unique survey that elicited revealed and stated preference data on household time allocation is used to implement the model. The results support the conclusion that there is an increasing marginal value of time for recreation as the trip length increases.
\end{abstract}

Raymond B. Palmquist

Department of Economics

North Carolina State University

Raleigh, NC 27695-8110

palmquist@ncsu.edu

Daniel J. Phaneuf

Department of Agricultural

and Resource Economics

North Carolina State University

Raleigh, N.C. 27695

dan_phaneuf@ncsu.edu

\author{
V. Kerry Smith \\ Department of Economics \\ W.P. Carey School of Business \\ P.O. Box 873806 \\ Arizona State University \\ Tempe, AZ 85287-3806 \\ and NBER \\ kerry.smith@asu.edu
}




\section{Short Run Constraints and the Increasing Marginal Value of Time in Recreation}

\section{Introduction}

Time may well be the ultimate scarce resource for many people in contemporary society. Choices about time allocation can signal consumer preferences about the balance between market and non-market activities. While these choices are made continually throughout each day, they are nonetheless undertaken within a defined set of constraints. Some are imposed by nature, such as the hours of daylight. Others are imposed by institutional conventions such as the distinction between weekdays and weekend days. Still others are the result of commitments made in earlier time intervals that constrain future patterns of time use. Some of these decisions have long-term consequences, such as labor market choices and retirement planning. Others are mundane and easy to adjust. These can include a multitude of everyday activities, such as running errands or taking a walk in a park. Since decisions about time allocation are made in different contexts and with different constraints, the marginal value of time to an individual may vary depending on prior commitments, context and the needs of the specific time use. Estimates of the value of time are especially important in understanding recreation demand.

Early work in recreation modeling has largely relied on established labor market models for estimating the shadow value of time. This pattern is also true for other sub-fields in economics where time allocation questions arise. The relationships between the opportunity cost of time and labor market choices have been assumed to apply equally well to long-term decisions about jobs and to short-run choices such as allocating time for a short recreation trip. While it stands to reason that these types of decisions involve substantially different choice margins, little conceptual or empirical research exists that differentiates the alternative time frames and analyzes their consequences for the shadow value of time. This paper presents a new approach 
for time valuation.

We propose and illustrate a new strategy for combining stated and revealed preference data to estimate how the value of time for short term decisions can be different from the shadow values implicit in long term labor market choices. The model and empirical results show that the short run value of time varies with the size of the block of time involved. By contrast, most empirical research on time has assumed time is fungible. Our starting point is that time, unlike many other resource endowments, is not perfectly fungible. The way total time is divided affects how it can be used. For example, one four-hour period of time allows different consumption possibilities than four one-hour periods. This notion of the imperfect divisibility of time, particularly over a short planning horizon, is central to our analysis. We highlight the fact that discretionary time is usually available in non-contiguous blocks of time, and it is not possible to move time freely between blocks. People do a variety of activities in these non-work blocks of time. Some activities can be broken-up into parts and partially reallocated between time periods. This type of decomposition may, however, entail greater costs. Other activities require contiguous blocks of time. Recreation is an activity that falls primarily in the latter category. The travel costs of outdoor recreation introduce indivisibility in time allocations. That is, it would be costly to replace a day-long recreation trip to a site with several shorter trips to the same site, and would likely involve different activities even if the total time used were the same.

Finding a block of time for recreation in one period may require shifting competing activities to other periods. Some of these activities may be necessary but not especially enjoyable, such as cleaning the house or tending the yard. It is likely that there is diminishing marginal productivity of time in these alternative activities in a given block of time, perhaps due to other fixed inputs or fatigue. This relationship implies that completing household tasks in one 
period in order to free another period for recreation would result in an increasing marginal opportunity cost of the time made available for recreation, as a greater amount of time is shifted.

Our conceptual model accounts for the imperfect divisibility of time. The assumption of different choice margins for time allocation is used in a two-step estimation strategy to measure the shadow values of different sized blocks of leisure time. We designed and conducted a new survey of homeowners in Wake County, North Carolina to test our framework. Our findings indicate the marginal value of time can increase by several percentage points for each additional hour included in the time block.

The remainder of the paper is organized as follows. Section 2 provides a short overview of previous research on the value of time and describes the strategic role that different choice margins play in each approach. Our theoretical model is developed in Section 3. In the model, an individual's time allocation decisions over sequentially unfolding short horizons are conditional on long term decisions such as employment. The short term decisions allocate blocks of time to recreation and "household maintenance". To obtain longer blocks of time for recreation, maintenance activities must be reallocated over time, and so the marginal value of time increases with the length of the block of recreation time. Because this conceptual model examines time use decisions over many short time periods, an empirical version would require panel data on household time use that is generally not available at reasonable cost. In Section 4 we therefore modify the model to enable a tractable empirical strategy that still addresses the central issue, which is the relative importance of time commitments in addition to employment in determining the opportunity cost of time. We investigate whether the time required for household activities is a commitment that can be displaced or broken up in some time periods to allow the accumulation of time for other tasks. This response is another margin of adjustment 
that is intermediate to changes in work commitments, and therefore may better reflect the short run value of time. The model requires data on representative individual time allocations as well as our stated preference question on substitutes for personal time in household chores. Section 5 describes the survey used to collect our data, while section 6 discusses the implementation and results. The last section discusses some general implications of the model and a summary of our overall findings.

\section{Previous research}

Numerous studies have questioned the use of the wage rate as the relevant opportunity cost of time, yet the profession seems far from a consensus on an alternative basis for estimating how individual circumstances and different types of decisions condition the relevant opportunity cost. In dealing with time, the existing literature has considered models that vary along three dimensions. The first involves if and how time enters preferences. The second considers how time budgets constrain choices, and how multiple money and time constraints are specified. The last describes how time 'prices' are associated with the consumption of final goods and services that contribute to well being.

Classic papers by Becker [1965], Johnson [1966], and De Serpa [1971] began the consideration of the allocation and value of time. They showed that the value of time need not be equal to the wage rate. While the earliest studies of the value of time were transportation related, the importance of the issue for recreation demand was also recognized in an early paper by Cesario [1976], which cites the transportation research in proposing a one-third the wage rate rule for valuing travel time. Shortly thereafter McConnell and Strand [1981] included mileagerelated travel costs and travel-time costs (measured using the wage rate) as separate arguments in a travel cost demand model to test the Cesario approximation. This strategy could also be 
interpreted as a test of the Becker [1965] full price logic in costing trips to recreation sites. Their results suggest that an individual is unable to perfectly exchange time units. ${ }^{1}$

In another important paper Bockstael, Strand, and Hanemann [1987] model recreation decisions conditional on whether individuals face limits on their ability to re-allocate time. In their case, time enters preferences as leisure. Recovering estimates of the opportunity cost of time requires understanding how agent's constraints condition what can be learned from observed time use. People differ in their work time environment. Those working full time may not be able to freely adjust work hours, and so we do not observe their opportunity cost of time through the wage rate. In cases where adjustment is possible, the rate of compensation maybe an overtime wage that can differ from the regular wage. These insights suggest the most effective way to account for differences in the shadow value of time is to classify individuals into flexible versus inflexible in their time allocation decisions. Thus, the Bockstael, Strand, and Hanemann logic for describing time allocation follows conventional labor economics and implies a piecewise linear budget constraint. Importantly, we learn very little about the value of time for individuals without flexible work hours. By contrast, the choices of flexible individuals do reveal an opportunity cost for time as their wage, while those with second jobs reveal an excess demand for work and a reservation value for leisure less than the wage on their primary job.

This implies there are important limitations in our ability to use labor market choices to measure shadow values of time. The only opportunity to use revealed preference information to recover measures for the value of time with traditional full time workers is through their decisions to change jobs. Using revealed and stated preference data Feather and Shaw [1999] illustrate one way to address this issue. Their approach adapts Heckman's [1974] labor supply model to recover some information about shadow values of time for individuals who are unable 
to adjust their work time. They use a simple stated preference question paralleling Heckman's strategy for recovering the shadow values of time for constrained individuals. They offer respondents the opportunity to relax their labor market constraints. People were told they could increase working time and receive additional earnings or they could decrease work with a corresponding reductions in earnings, each at a constant wage rate corresponding to their hourly rate. Survey respondents' answers determine whether a non-flexible individual's existing wage is an upper or lower bound on their reservation wage. By combining flexible and non-flexible individuals Feather and Shaw identify a reservation wage equation for all labor market types. In short, their framework reveals the long run shadow value of time based on a set of stated opportunities to renegotiate employment conditions.

Larson and Shaikh [2001] and Shaikh and Larson [2003] extended the two-constraint model in several directions. The value of time is reflected in the relative scarcity of time versus money in the task of maximizing utility. Each person has a unique opportunity cost of time that is the same regardless of how it is used. All time is fungible and interchangeable, but its shadow value need not equal the wage. In the most recent application of this two constraint model, Lew and Larson [2005] demonstrate how a joint framework linking the Feather-Shaw strategy to Larson and Shaikh model can control for unobserved heterogeneity in a mixed logit model for recreation site choice. However, their framework requires that the shadow value of time be invariant to the timing of the decision. Although the shadow value varies with individual characteristics, it is constant for choices based on daily, weekly, and annual time budgets.

Several lessons emerge from the literature to date. While early conceptual research highlighted the different margins at which time allocations are made, empirical models were not able to incorporate them into the measurement of the implied values for time. What appears to 
be missing is recognition that some time allocation choices create cascading commitments on both the amounts and the margins for decisions in later time choices. For example, job decisions limit the discretion in labor-leisure choices. Depending on the job they can involve quasi-fixed commitments to work at specific times for specific periods of time. It seems reasonable to assume these types of choices reflect a longer run time horizon and are taken as given when an individual plans weekly leisure activities. They are also likely to be considered fixed in planning day trips or longer recreation outings. This hierarchical decision structure is an alternative to the model in Lew and Larson, which jointly estimates the job choice decision and the beach trip decision. In contrast, our model recognizes that people attempt to make commitments to jobs that will be consistent with what they anticipate will be their subsequent short term time needs. Models for short run choices should consider time's role both as a constraint on choice and as an input in the production of utility-generating services. The framework used to estimate the opportunity cost of time should reflect the relative scarcity of time and money in the planning horizon that is relevant to the choices under analysis.

\section{Conceptual Model}

Our model of individual behavior assumes decisions take place over different time horizons. This formulation allows us to explore time-related insights without reliance on a less tractable dynamic model. ${ }^{2}$ We begin by noting that different types of commitments are made by individuals. Each of these can limit the discretionary uses available to the time remaining. The largest commitments stem from employment and residential location decisions, which are not easily changed and are assumed to be part of long run choices. Other decisions also imply longer term time commitments. For example, decisions such as owning a house, having children, or purchasing a pet have implications for a household's time commitments. These choices can 
require repeated home production tasks such as preparing food, caring for dependents, cleaning the house, feeding and exercising a pet, and tending the yard. We label this class of activities as 'household maintenance'. There are two important aspects of these commitments. First, the amount of time spent on them can vary over short periods largely by displacing the timing of the activities or delaying some tasks. Nonetheless, the needs motivating the time do not go away unless the nature of the commitment is changed. So in the longer term displaced time needs to be made up. Second, the total level of maintenance is determined by the personalities and habits of the members of each household, so we expect to observe differences in the importance of these commitments and differential effects on their opportunity costs of time. For short-run decisions, including day-trip recreation behavior, households take employment, residential location, and total maintenance over the long term as predetermined. ${ }^{3}$

Ideally, one would use a panel of choices over time to learn, through adjustments in these commitments, the full dimensions of each individual's opportunity costs of time. A necessary condition for this type of analysis is the ability to observe people's responses to temporally delineated constraint sets through unique diary-type datasets. Our strategy mimics but avoids this fully detailed description by using a set of real and hypothetical choices, together with the envelope conditions they imply, to recover the shadow values for different types of time adjustments.

We begin our model by assuming that short-run decisions unfold over $J$ weeks. Each week offers the same discretionary time (which can be allocated to leisure activities and maintenance) as any other week. Let $T^{j}$ represent the total amount of non-work (and non-sleep) time that is available in week $j$. This time is used for household maintenance and short term leisure activities such as recreation activities. We denote the output of maintenance in week $j$ by 
$M^{j}$, and assume that $M^{j}$ is strictly positive. The individual produces maintenance in week $j$ using own time denoted $t_{m}^{j}$ and purchased inputs. The maintenance production function is defined by $M^{j}\left(t_{m}^{j}\right)$, where purchased inputs are suppressed for notational convenience. The marginal product of own time is assumed to be positive but exhibits diminishing returns. While maintenance is defined for each week, we also assume it is possible to shift maintenance activities between weeks. ${ }^{4}$ This shifting is a key element in isolating the short-term, intertemporal substitution that identifies how people tradeoff non-work time uses. Total maintenance, $M$, is the sum of maintenance in the various weeks and is predetermined. In the absence of other considerations, if the weekly maintenance functions were the same, each individual would spend equal amounts of time each week to minimize the total time costs of reaching the fixed level of total maintenance. ${ }^{5}$ To the extent the functions differ by week, time would be allocated to equalize implied marginal costs of producing the required level of total maintenance. Other uses of non-work time, however, imply the allocation is more complex.

In our model, the alternative use of non-work time is local recreation, $R^{j}$. Recreation is produced using time spent in the activity and complementary purchased goods, such as out-ofpocket travel costs. Again suppressing these other inputs for notational convenience we denote the recreation production function for week $j$ by $R^{j}\left(t_{r}^{j}\right)$ where $t_{r}^{j} \geq 0$, so that recreation can be zero in a given week. The marginal product of time for recreation is positive, and the marginal productivity of time in recreation is increasing over the relevant range. Though asserted rather than tested, the local convexity of $R^{j}(\cdot)$ seems reasonable. As a larger block of time becomes available constraints on activity choices are relaxed (longer-commitment activities become possible), thereby expanding the utility-generating options inherent in the block. Thus our 
maintained assumption is that larger blocks of recreation time are more useful in producing recreation.

The individual gets satisfaction from allocating time to the leisure activity (recreation) and from purchased goods. Purchased goods are denoted by $x$, where price has been normalized to one, and income for the period is $y$. The individual allocates non-work time and income to maximize utility subject to income and time constraints as well as to the maintenance requirement. Formally the individual solves the constrained maximization problem

$$
\max _{t_{m}^{j}, t_{r}^{j} \forall j} U\left(R^{1}\left(t_{r}^{1}\right), \ldots, R^{J}\left(t_{r}^{J}\right), x\right) \quad \text { s.t. } \quad T^{j}=t_{m}^{j}+t_{r}^{j} \forall j, \quad y=x, \quad M=\sum_{j} M^{j}\left(t_{m}^{j}\right) .
$$

This model combines elements from several earlier treatments of time. Time can make different contributions to utility through the various $R$ 's. There could also be contributions from both work and maintenance time allocations. These are not explicitly entered in this definition of the choice problem because both are assumed to be pre-determined as part of long-run decisions. Inverting the $J$ time constraints and substituting them into the maintenance function reduces the $J+2$-constraint problem to a more familiar two-constraint case with maintenance serving a role comparable to the time constraint:

$$
M=\sum_{j} M^{j}\left(T^{j}-t_{r}^{j}\right)
$$

Maximizing utility subject to (2) and the income constraint leads to solutions for the optimal time allocation and the indirect utility function $V\left(y, T^{1}, \ldots, T^{J}, M\right)$. With $\lambda$ and $\mu$, the Lagrangian multipliers for money and maintenance, respectively, the Envelope Theorem implies $V_{y}=\lambda$ and $V_{M}=\mu$. More importantly we also have:

$$
V_{T_{j}}=\mu \frac{\partial M^{j}}{\partial T^{j}}=\mu \frac{\partial M^{j}}{\partial t_{m}^{j}} .
$$


The marginal utility of time depends on the marginal product of time in maintenance. As a result, the marginal opportunity cost of time in time period $j, \rho^{j}$, can be defined in terms of this household production activity.

$$
\rho^{j}=\frac{V_{T_{j}}}{V_{y}}=\frac{\mu}{\lambda} \frac{\partial M^{j}}{\partial t_{m}^{j}} .
$$

Maintenance's role as a recurring activity offers repeated time allocations, which provide opportunities for short term adjustments. Properties of the maintenance activity imply, for given values of $\mu$ and $\lambda$, the marginal value of time is larger when the marginal product of time in maintenance is larger. ${ }^{6}$ If little time is spent on maintenance, the marginal productivity of maintenance effort is high, and the opportunity cost of spending that time in leisure activities is also high. As a consequence, the shadow value of different blocks of recreation time will depend on their size (i.e., the amount of time that must be assembled). Total and marginal utility from recreation are dependent on the amount of time available to produce the experience. It may be optimal to reallocate maintenance across periods to assure that more time is available for longer recreation trips. For a given individual these choices can result in differing marginal values of time for trips of different lengths. The challenge is designing an empirical strategy to measure these different values. This task is especially problematic when one considers the challenges in collecting data on people's time allocations (see Kahneman, et al [2004] for discussion of some aspects of this issue). In the next section we describe simplifications to our model that are needed to test the framework with data collected from a single cross sectional sample.

\section{Empirical Strategy}

The model in the last section is based on choices within individual weeks. We recognize that the time spent in both recreation and maintenance can vary by week. In the absence of a panel with detailed records on time use patterns across individuals, we structured hypothetical 
choices along with the specification of the production function for household maintenance to learn how the opportunities to adjust some aspects of one's commitments influence time tradeoffs. An individual's marginal value of time for recreation in a given week will vary depending on the time she spends in recreation. In addition, her marginal product of maintenance depends on the time she spends on maintenance that week. Because of the overall time constraint for recreation and maintenance time, the two decisions are linked. If we can estimate the household production function for maintenance, we can use the results to derive estimates of the value of time. Our strategy uses data on the household's maintenance and other activities for a "typical" week, and the household's response to a stated preference question providing a market opportunity to purchase maintenance services. The question offers an option to purchase (at a fixed hourly price $w_{s}$ ) regularly scheduled hours of weekly services that can be used for maintenance (i.e., lawn services, cleaning services, and a variety of other time saving market services).

For the empirical model we assume an individual's utility for a representative week is given by $U(x, H ; \bar{M})$ where $\bar{M}$ is average time per week devoted to maintenance and is predetermined. ${ }^{7} H$ represents leisure of all types including recreation. Let the individual's labor devoted to household maintenance production be $L$ and purchased hours of maintenance service labor be $L^{S}$. We define $f(L)$ to be the contribution to total maintenance from own labor, where $f^{\prime}(L)>0$ and $f^{\prime \prime}(L)<0$, and we normalize the units for maintenance so that one hour of professional service provides one unit of maintenance. Maintenance is therefore the total of own and purchased production, given by

$$
\bar{M}=f(L)+L^{S} .
$$


Utility is maximized subject the budget constraint $y=x+w_{s} L^{S}$, (where $x$ is the numeraire and $w_{s}$ is the price per hour of purchased maintenance) and time constraint $T=H+L$. Substituting the time constraint and the maintenance function in (4) into the budget constraint yields

$$
y=x+w_{s}[\bar{M}-f(T-H)] .
$$

There are two types of solutions to this utility maximization problem. The first involves individuals who purchase a positive amount of service at the offer price, resulting in an interior solution. In this case, the value of time in a typical week with the option of purchased maintenance services, $\rho^{\mathrm{s}}$, is

$$
\rho^{s}=\frac{U_{H}}{U_{x}}=w_{s} f^{\prime}(T-H){ }^{9}
$$

In the second case we have individuals who choose not to purchase service at the offered price. As a result, it is not possible to collapse the maintenance and time constraints into the budget constraint. The value of time for these individuals is determined by a corner solution in the purchased service market:

$$
\rho^{s}=\frac{U_{H}}{U_{x}}=\frac{\mu}{\lambda} f^{\prime}(T-H)<w_{s} f^{\prime}(T-H),
$$

where $\mu$ is the Lagrange multiplier for the maintenance constraint.

Estimating equations can be derived from (6) and (7). Using censored regression and a specification for $f$ we can estimate a transformation of the weak inequality

$$
\frac{\rho^{s}}{w_{s}} \leq f^{\prime}(L),{ }^{10}
$$

where $L$ is the amount of own maintenance labor when the service is available at a price $w_{s}$ and $\rho^{s}$ is the mean value of time, which is determined in the long run. We use the Feather and Shaw (1999) approach, discussed in section 2, to estimate the long run work/leisure tradeoff. The 
responses to our actual and hypothetical behavior survey questions allow equation (8) to be estimated. Our description of the hypothetical service is presented in the next section.

Once the marginal product function has been estimated it is possible to calculate the value of the marginal product for each individual's own maintenance labor in the absence of the hypothetical purchased personal service. This is the marginal product evaluated at the observed allocation of personal labor to maintenance in the baseline, designated here as $L^{*}$. With the baseline marginal product and the long term value of the shadow wage $\rho^{s}$ it is possible to calculate $\mu / \lambda$, the marginal value of maintenance as:

$$
\frac{\mu}{\lambda}=\frac{\rho^{s}}{f^{\prime}\left(L^{*}\right)} .
$$

Since decisions about work time and overall maintenance levels are determined in the long run, the marginal utilities of income and of maintenance are constant over the short time period that is the focus of this analysis. Thus, the primary influence on the short run value of time from equation (3) will be due to time allocated to maintenance in a particular week. If a person wants to enjoy additional recreation during the week, he needs to adjust his time allocation accordingly. The resulting reduction in maintenance activities has an increasing marginal opportunity cost, in that progressively more productive hours of maintenance are given up to produce additional recreation. The forgone maintenance is made up in other time periods, but with reduced productivity, due to the diminishing marginal product of time in maintenance. With estimates for the marginal product of maintenance as well as the long-horizon shadow wage, our model allows estimation of the time cost of varying recreation time allocations. The details of this procedure are given in Section 6. 


\section{Data}

The data used here were collected as part of a larger effort that sought to integrate residential housing sales information, survey data on homeowners' recreational activities, and their household characteristics, within a spatially delineated framework that allows inclusion of detailed information on the quality of the recreation sites. The focus of this analysis is on the components of the survey that requested information on household time allocation decisions. Between May and September 2003 a mail survey was sent to a sample of homeowners in Wake County, North Carolina, USA. The target population was homeowners who had purchased their homes between 1992 and 2001. A random sample of 9,000 of these households, stratified by geographical location, was drawn from this population. To verify that the survey would be sent to the owner (and resident) of the house, the addresses listed for tax purposes were cross checked with names and addresses of the individuals purchasing each house. The sample was limited to cases where the addresses of the housing unit and the individual receiving the tax bill matched. 7,554 surveys reached valid addresses where it would be possible to receive a response. ${ }^{11}$ The Dillman (1978) method for mailed surveys was followed with two mailings and a reminder postcard. Returned surveys amounted to 31.7 percent of the mailings to correct addresses. After screening for missing and implausible values, there were 1,719 useable responses for this analysis. ${ }^{12}$ The sample for this analysis is less than the number of returned valid questionnaires due to item non-response.

Our response rate is at the lower end of what conventionally has been considered desirable based on experience in the nineties. However, recent research on the topic suggests that low response rates alone do not signal non-response bias. For example, Holbrook, Krosnick, and Pfent (2005) conclude their detailed evaluation of 100 random digit dialed telephone studies 
over a 10 year period noting that "...lower response rates seem not to substantially decrease demographic representativeness within the range we examined" (p.38). ${ }^{13}$ Our comparison with Census information suggests our survey is consistent with their findings. To confirm this, we also estimated a selection model. The results are virtually identical to those from the estimation described here. The coefficient of the inverse Mills ratio is not significant at the $5 \%$ level and the coefficients of each of the variables are not different between the two equations. There is also no economically significant difference in the resulting marginal values of time. Since nonresponse bias appears to make no significant difference, we have not included the adjustment for it here. $^{14}$

Two aspects of the questionnaire are directly relevant to our model. First, we solicited time usage for the respondent and spouse (if any) for fifteen activities including primary and secondary employment, commuting, and a wide variety of non-work activities. The survey also includes questions about how much paid help the household hired for maintenance services, and whether they could freely choose how much time they allocated to each of the activities. In addition, we asked about the flexibility they had in their work time. Our survey also asked labor supply choices using the same question developed by Feather and Shaw (1999). ${ }^{15}$

Second, each household was asked about a personal assistance service (i.e., the stated choice question discussed earlier) that offers a substitute for each respondent's time in household tasks. After describing the services available and presenting a randomly-assigned ${ }^{16}$ market price per hour, we asked if the respondent would purchase the service and, if so, how many hours in a typical week. The framing of the question implies that it could be used for any of the activities undertaken by adults in the household. We assume all hours allocated to household maintenance can be aggregated. The personal assistant question was followed by several regarding how 
respondents would use any time made available by purchasing the service. The specific question about the potential purchase is reproduced in the Appendix. ${ }^{17}$ We also collected information on the earnings and non-labor income of the household, job characteristics, and a variety of other socio-economic variables. The variables definitions and descriptive statistics are given in Table 1.

Households' reports of the time devoted to household activities (e.g. cleaning, cooking, etc.); yard work/gardening; activities related to your children; and shopping for routine needs/running errands were assumed to correspond to maintenance. Following the unitary household assumption the times reported for the respondent and the spouse or partner (if present) were combined. The amount of time for household maintenance is assumed to be the sum of times reported in these four categories. Time allocated to maintenance when the hypothetical personal services are available is estimated by subtracting stated time purchases from the baseline measure of their time allocated to maintenance. ${ }^{18}$

\section{Empirical implementation and results}

Our estimation of the short-run value of time function for households requires estimates of the long-run shadow wage. The Feather and Shaw (1999) framework assumes the market and shadow wages are equal for respondents with flexible work schedules. For unemployed, underemployed, and over-employed people the relationship between the shadow and market wages is an inequality. The model begins with specifications for the shadow and market wage equations

$$
\begin{gathered}
\rho_{i}^{s}=\Omega_{1} F_{1 i}+\alpha h_{i}+\varepsilon_{i} \\
w=\Omega_{2} F_{2 i}+u_{i},
\end{gathered}
$$

where $\rho_{i}^{s}$ and $w_{i}$ are person $i$ 's shadow and market wages, respectively, $\mathrm{F}_{1 i}$ and $F_{2 i}$ are sets of

exogenous variables, $h_{i}$ is hours of work, $\left(\Omega_{1}, \Omega_{2}, \alpha\right)$ are parameters, and $\varepsilon_{i}$ and $u_{i}$ are error terms. 
The form of the estimating equation for each person in the sample depends on their responses to the question about adjusting their hours. For flexible workers the relationship $w_{i}=\rho_{i}^{s}$ holds, while we have $w_{i} \leq \rho_{i}^{s}$ and $w_{i} \geq \rho_{i}^{s}$ for under- and over-employed people, respectively. For unemployed people $w_{i} \leq \rho_{i}^{s}$ also holds, where in all cases $\rho_{i}^{s}$ is evaluated at the observed level of $h_{i}$. If we assume the errors are jointly normal, these inequalities can be used to bound the support of error values that are consistent with observed outcomes, and maximum likelihood can be used to estimate the parameters of the shadow wage and market wage functions.

Our specifications for these functions follow the original Feather and Shaw application. The shadow wage function includes a constant and variables for work hours, non-work income, spouse work hours, and qualitative variables indicating the presence of young children, gender, and an interaction term between gender and the presence of young children. The market wage function includes a constant and variables for age, education, and indicators of race and gender. The parameter estimates are given in Table 2 . The estimates are generally consistent with $a$ priori expectations with most coefficients significant at conventional levels. For the individuals in our sample, the mean predicted shadow wage is $\$ 26.64$ and the median is $\$ 19.61$ (in 2003 dollars).

Estimation of the marginal product of maintenance requires specification of the personal maintenance production function. We expect that this function would vary by individual and exhibit diminishing marginal product. We focused on two specifications for this function, a log form and a quadratic form. The results were quite comparable. Since the quadratic form introduces more flexibility, those results are presented here. ${ }^{19}$

The simple quadratic household production is

$$
f(L)=a L^{2}+b L .
$$


This form allows testing for diminishing MP. A vector $z$ including any observable individual/family characteristics that might influence productivity can be included in this equation. Inverting the marginal product function implied by equation (11) and using the equality form of the first order condition given in equation (8) (recalling that $\rho^{s}$ is the shadow wage and $w_{s}$ is price of personal services), the estimating equation is then.

$$
L=\beta_{0}+z \beta_{z}+\beta_{1}\left(\frac{\rho^{s}}{w_{s}}\right)+\varepsilon
$$

Algebraic transformations allow the structural parameters of the marginal product for time in maintenance to be recovered from the estimated coefficients. That is: $\beta_{1}=1 /(2 a)$ and $\beta_{0}+z \beta_{z}$ $=-b /(2 a)$, or $a=1 /\left(2 \beta_{1}\right)$ and $b=-2 a\left(\beta_{0}+z \beta_{z}\right)$. Thus, the prediction would be $\beta_{0}>0$ and $\beta_{1}<0$. With this functional form it is possible to have estimates for the $\beta$ s that imply the marginal product is not positive even for parameters with the theoretically predicted signs. A positive marginal product would be consistent with a rational time allocation in our model. Thus, this feature offers an indirect empirical test for the framework.

The dependent variable is the number of hours devoted to household maintenance. We use maximum likelihood assuming a censored normal distribution for the error. The estimates are presented in of Table 3. Column two reports a parsimonious specification that includes relative price and a constant. Even in this specification, the marginal product is positive in the range of the data and diminishing as expected. Our two step estimation strategy uses an estimate of the conditional expectation for $\rho^{S}$ in the numerator of the ratio of shadow value to service price. As a result, the estimated model is expected to have a non-spherical error. To take account of this issue, all of our tests use Huber's (1967) robust covariance matrix for the estimated model parameters. 
We hypothesize that the characteristics of households also play an important role in explaining the differences in behavior with respect to maintenance. Column three of Table 3 provides the results for a more complete specification. There are a number of factors that play a significant role in the maintenance decisions. Households with higher labor income and thus probable higher opportunity costs of time do less own maintenance. Households where a "significant other," typically a spouse, is present do more own maintenance production. Recall that maintenance is the sum of both members' home production, so this does not represent any substitution within the household but rather a difference by household type. The number of family members in the house also increases maintenance. There is some support for the logic associated with our unitary household model in that the sex of the respondent was not a significant variable in this or other specifications and was not included. Similarly, race was never significant and was omitted. Age is not significant here but was included since it displayed some explanatory power in other specifications.

The difference in the number of hours worked by the respondent compared to his or her spouse is also hypothesized to influence reported own maintenance. Our formulation of this effect codes this variable in qualitative terms with one indicating that the respondent works at least ten hours more per week than the spouse, a zero if there is less than a ten hour difference between the work weeks for the couple, and a negative one if the respondent works at least ten hours less than the spouse. This variable was included to control for any differences in perceptions depending on the relative workforce participation of the respondent compared to the spouse in the household. ${ }^{20}$ It is not significant in column three but is in the more complete specification in column four. This pattern is repeated with the work flexibility variable. 
The fourth column in the table reports the last and most complete specification of the model. The first of the additional variables uses the number of non-work hours calculated in two ways. The first uses the number of hours in a week and subtracts the number of hours that respondents reported they devoted to all employment plus the time spent commuting plus an allowance for time spent sleeping. We expect the respondent to be quite accurate in reporting work and commute time. As a result, this measure probably represents a fairly accurate measure of non-work time. The second strategy simply uses the total of all the time reported for nonwork activities. The difference in the two measures captures the accuracy and completeness of the respondent's accounting for non-work time. ${ }^{21}$ As expected, if the accounting for non-work activities in general was higher, the reported time spent on maintenance was also higher.

The other two variables included in this full specification are based on the responses to the question about what survey respondents would do with the new time made available by employing the hypothetical personal services. The variables are dichotomous variables for those who said they would work longer hours and for those that said they would devote the time to housework. The omitted category was for those who would use the time for leisure activities. The individuals who would take more leisure tended to report more time spent on maintenance. Finally, the time flexibility measure is positive and significant, whereas in the previous specification it was not significant. Households where there was flexibility in shifting the work schedule devote more time to household maintenance. Diminishing marginal product in household maintenance is more of an issue if work hours cannot be shifted, so this is a plausible result.

This last specification of the quadratic model is our preferred model and is used in calculating the value of different blocks of time. In estimating the household's maintenance 
services production function, we used the exogenous price of purchased services that was given in the stated preference question. However, the individual's actual value of time is based on her actual choices. Therefore, to calculate the value of time using equation (6), we use the marginal product of own labor computed at the actual level of household services, rather than the level if the purchased services were available. If maintenance is then shifted to allow for recreation, it increases the marginal product of maintenance and raises the marginal cost of time for recreation. By this logic different marginal values of time can be calculated for different length trips.

Specifically, from equations (3) and (9) we can express the short run marginal value of recreation time $(M V T)$ as

$$
\operatorname{MVT}(t)=\frac{\rho^{s}}{f^{\prime}\left(L^{*}\right)} \times f^{\prime}\left(L^{*}-t\right)
$$

where $L^{*}$ is the actual amount of maintenance expected per week, $t$ is the amount of maintenance time displaced by recreation, and estimates of the parameters in $f(\cdot)$ come from Table (3). Note that $M V T(t)$ is increasing in $t$ due to the diminishing marginal product of time in maintenance. Equation (13) shows that a given individual's value of time will be influenced by her long run shadow wage and by her individual characteristics, since the maintenance production function includes these variables. This means that for a given length trip, there is a distribution of marginal values of time between the individuals in the sample. Table 4 provides the sample quantiles of the distribution of the predicted marginal value of time for blocks of recreation time that displace 2, 4, 6, and 8 maintenance hours, as well as the long-run shadow value of time of these individuals. The marginal value of time increases as the proposed blocks of recreation time become longer. 
Our framework has several important implications for recreation research. First, the opportunity cost of time spent in travel and on site is arguably the largest component of the costs of local and day recreation trips. To provide a sense of the potential importance of the treatment of these costs Table 5 presents summaries for the total opportunity cost of time measured using four different time valuing strategies for trips of varying lengths. We report the sample mean of the baseline marginal value of time and the sample mean total value of time for $2,4,6$, and 8 hour combinations of travel and onsite time. For the one-third the wage rate, wage rate, and Feather and Shaw strategies the marginal value of time is constant, and so the total time values are simple products of the opportunity cost estimate and the time involved. For our approach the marginal value is not constant, so we obtain the total value of the block of time by integrating $M V T(t)$ in equation (13) from zero to the trip length $t$, where $t=2,4,6,8$ in the table. The results using the wage rate or one-third the wage rate are quite different from the results using our measure, as might be expected. We focus our comments on the differences between our model and the Feather and Shaw model, since the two provide identical baseline marginal values. For short trips the differences in the total time costs of the trip are relatively small. However when a four hour block of time is accumulated, the total value increases by nearly five percent. This climbs to nearly ten percent for eight hour trips.

Second, the framework implies that when the marginal value of time does change appreciably with the amount of time, conventional demand (and random utility specifications for choice models) will need to be revised to incorporate the full implications of nonlinear budget constraints for the choice process. Ideally a fully integrated model would link recreation choices with the adjustments considered in altering time constraints as implied by the envelope conditions we used to develop or estimates. Short of such a complete framework our estimates 
suggest it may be desirable to adapt the methods used for measuring benefits of changes in access conditions or the quality of local recreation sites using an extension to the framework proposed by Reiss and White [2006]. Finally, our analysis reinforces the need for micro models of individual behavior to deal more explicitly with individual heterogeneity in constraints and preferences.

\section{Conclusion}

People's choices about their time allocations take place on a variety of margins and timeframes. They are made sequentially with some choices constraining others that come later (at least until the consequences are important enough to warrant incurring the costs of revision). This recursive structure has been implicitly discussed in the environmental economics literature, but its implications have not been fully utilized. In this paper we have shown that it is possible to use the different margins on which time allocations occur to estimate a shadow value of time that is partially decoupled from the labor market, and is appropriate for short run choices. In doing so we have shown how non-work choices can convey information on the value of time. Many recreation activities require blocks of time, and the value of time for these activities may differ depending on the size of the block. This is because constraints on how time can be assembled are imposed by its imperfect transferability, and choices must be made if a larger time block is desired. Our strategy for valuing time for recreation has used information from revealed and stated preferences together with a recognition that decisions represented in each of these sources of choice information may well be made in quite different time frames. The results indicate that the marginal value of time can be increasing as the size of the block time increases.

This finding has implications for valuing different types of recreation experiences. For example, small blocks of time are adequate for a visit to a local park, while larger blocks are 
necessary for trips to a regional park. For a given individual the marginal value of time devoted to the latter trip will be higher. Similarly, these findings also have implications for assigning the values of time to visitors living different distances from a site. The greater the distance, the greater is the time commitment, and the higher is the relative value of time.

Our research has focused primarily on developing methods for valuing time used in local recreation outings for non-market valuation purposes. It is worth noting, however, that our approach has applicability for a wide range of extra-market valuation problems. In particular there has been recent discussion of methods needed for augmenting the national income and product accounts to reflect non-market activities (see Nordhaus [2006] and Frazis and Stewart [2007]) as well as attention to non-work time allocation in general. For any research involving non-work time allocation at least two definitional challenges must be met and made operational. The first concerns defining the utility-generating non-market outputs that time contributes to, and the second concerns defining and measuring a 'price' for these outputs. Landefeld and McCulla [2000] address the definition of outputs, describing the so-called third person test. In this case the household produced outputs are defined based on the potential substitutes available in the market. Our maintenance function is an operational example of this strategy in that we define the commodity in terms of its purchased substitute. Importantly, it also highlights the critical role of the time horizon in defining the non-market output. This is a point that has received less attention in the general time allocation literature, but is closely related to the second definitional challenge. Frazis and Stewart [2007] describe two ways to price household produced outputs: using the market wage of the household member, and valuing the output by its market replacement cost. Dissatisfaction with the former has been expressed for many of the reasons long cited in the environmental economics literature, yet as an alternative it seems that the latter 
ignores the crucial issue of the individual's opportunity cost of time. ${ }^{22}$ What is missing is the recognition that the frequency and timing of the non-market activities matter, and that short run time constraints and the production technology imply a shadow value of time (and hence opportunity cost of the non-market output) that need not be equal to the wage rate. Our research shows how a strategic stated preference question might be used to define the non-market commodity, partially understand its production technology, and assess its shadow value. We also demonstrate the importance of including questions in time use surveys that acquire information about the decisions on how much home production to undertake as a means of gauging short run time constraints and values.

Finally, our empirical application highlights a new role for stated choice questions. Most applications in environmental economics have focused on new choices, offering individuals the opportunity to decide about an amenity that has previously been outside the domain of their choice set (or one where it was difficult to make large changes). In addition, many previous efforts at joint estimation were designed to use revealed preference data to calibrate stated preference responses. Our model relies on an integrated strategy in which the stated preference model offers a different type of choice margin that may serve to relax time constraints for some individuals. This new information can be combined with data on actual time allocation decisions to recover a better description of how differential time constraints among individuals influence the choices they make involving the mixes of goods and time consumed. 


\section{References}

Becker, Gary S. [1965]: “A Theory of the Allocation of Time,” Economic Journal, 75(September): 493-517.

Bockstael, Nancy, Ivar Strand, and W. Michael Hanemann [1987]: “Time and the Recreational Demand Model,” American Journal of Agricultural Economics, 69(2): 293-302.

Cesario, Frank J. [1976]: "Value of Time in Recreation Benefit Studies” Land Economics, 52(February):32-41.

DeSerpa, Alan [1971]: “A Theory of the Economics of Time,” The Economic Journal, 81(324): 828-846.

Dillman, Don R. [1978]: Mail and Telephone Surveys: The Total Design Method, New York: John Wiley \& Sons,

Feather, Peter M., and W. Douglass Shaw [1999]: "Estimating the Cost of Leisure Time for Recreation Demand Models," Journal of Environmental Economics and Management, 38(1): 49-65.

Frazis, Harley and Jay Stewart [2007]: "Where Does Time Go? Concepts and measurement in the American Time Use Survey," in Hard-to-Measure Goods and Services: Essays in Memory of Zvi Griliches, edited by E.R. Berndt and C.M. Hulten (Chicago: University of Chicago Press for the National Bureau of Economic Research).

Hall. Robert E. [2009]: "Reconciling Cyclical Movements in the Marginal Value of Time and the Marginal Product of Labor", Journal of Political Economy,117(2): 281-323.

Hamermesh, Daniel S. [2005]: "Routine," in The Economics of Time Use, edited by D.S. Hamermesh and G.A. Pfann), (Amsterdam, Elsevier). 
Heckman, James [1974]: “Shadow Prices, Market Wages, and Labor Supply,” Econometrica, 42(4): 679-694.

Holbrook, Allyson L., Jon A Krosnick, and Alison Pfent [2005]: "The Causes and Consequences of Response Rates in Surveys by the News Media and Government Contract Survey Research Firms," discussion paper.

Huber, P.J. [1967]: “The Behavior of Maximum Likelihood Estimates under Non-Standard Conditions." in Proceedings of the Fifth Symposium on Mathematical Statistics and Probability. Berkeley, CA: University of California Press.

Johnson, M. Bruce [1966]: “Travel Time and the Price of Leisure,” Western Economic Journal 4: $135-145$.

Kahneman, Daniel, Alan B. Krueger, David A. Schkade, Norbert Schwarz, and Arthur A. Stone [2004]: “A Survey Method for Characterizing Daily Life Experience: The Day Reconstruction Method,” Science, 306(December): 1776-1780.

Keeter, Scott, Carolyn Miller, Andrew Kohut, Robert M. Groves, and Stanley Presser (2000): "Consequences of Reducing Nonresponse in a National Telephone Survey." Public Opinion Quarterly. 64, 125-148.

Landefeld, J. Steven and Stephanie H. McCulla [2000]: “Accounting for Non-market Household Production Within a National Accounts Framework," Review of Income and Wealth, 46(3): 289-307.

Larson, Douglas M. and Sabina L. Shaikh [2001]: "Empirical Specification Requirements for Two-Constraint Models of Recreation Choice," American Journal of Agricultural Economics, 83(2): 428-440. 
Lew, Daniel K. and Douglas M. Larson [2005]: “Accounting for Stochastic Shadow Values of Time in Discrete-choice Recreation Demand Models,” Journal of Environmental Economics and Management, 50(2): 341-361.

McConnell, Kenneth E. [1999]: "Household Labor Market Choices and the Demand for Recreation," Land Economics, 75(3): 466-477.

McConnell, Kenneth E., and Ivar Strand [1981]: "Measuring the Cost of Time in Recreation Demand Analysis: An Application to Sportfishing," American Journal of Agricultural Economics, 63 (Feb):153-156.

Nordhaus, William D. [2006]: "Principles of National Accounting for Non-Market Accounts," in A New Architecture for the U.S. National Accounts edited by D.W. Jorgenson, J.S. Landefeld and W.D. Nordhaus (Chicago: University of Chicago Press for National Bureau of Economic Research).

Reiss, Peter C. and Matthew W. White [2006]: "Evaluating Welfare with Nonlinear Prices," NBER Working Paper No. 12370, July.

Shaikh, Sabina L., and Douglas M. Larson [2003]: “A Two-Constraint Almost Ideal Demand Model of Recreation and Donations," The Review of Economics and Statistics, 85(4): 953-961.

Smith, V. Kerry, William Desvousges, and Matthew McGivney [1983]: “The Opportunity Cost of Travel Time in Recreation Demand Models," Land Economics, 59(August): 259-278. 
Table 1: Variable Definitions and Summary Statistics

\begin{tabular}{|c|c|c|}
\hline Variable Definition & Mean & Std. Dev. ${ }^{a}$ \\
\hline Hours of household maintenance & 42.40 & 29.83 \\
\hline Personal services price & 21.26 & 16.01 \\
\hline Respondent's labor income & 65,346 & 50,477 \\
\hline Spouse, etc. in household & 0.866 & - \\
\hline Number of family members in house & 2.97 & 1.36 \\
\hline Age & 44.46 & 9.84 \\
\hline Work distribution in household & 0.18 & - \\
\hline Flexibility in work hours & 0.12 & - \\
\hline Accuracy and completeness of response & -69.49 & 52.01 \\
\hline Choose more paid work & 0.04 & - \\
\hline Choose more housework & 0.20 & - \\
\hline Work hours & 31.39 & 21.33 \\
\hline Non-work income & 43,780 & 52,706 \\
\hline Spouse hours & 24.88 & 22.92 \\
\hline Kids $<6$ & 0.444 & 0.793 \\
\hline Male & 0.47 & - \\
\hline Black/Hispanic & 0.07 & - \\
\hline Education & 6.32 & 1.70 \\
\hline Wage (2003 dollars) & 38.05 & 78.67 \\
\hline Shadow wage (2003 dollars) & 26.65 & 33.50 \\
\hline
\end{tabular}

${ }^{\mathrm{a}} \overline{\mathrm{Standard} \text { deviation not given for discrete variables }}$ 
Table 2: Shadow Wage Estimation ${ }^{\mathrm{a}}$

\begin{tabular}{lcc}
\hline \hline Shadow wage variables & $\underline{\text { Estimate }}$ & t-statistic \\
\hline Constant & 0.4209 & 1.55 \\
Work hours & 0.0661 & 7.293 \\
Non-work income & 0.0455 & 4.71 \\
Spouse hours & -0.0097 & -4.472 \\
Kids $<6$ & 0.7184 & 6.668 \\
Kids $<6 \times$ male & -0.7553 & -5.63 \\
Male & -0.0799 & -0.492 \\
Market wage variables & & \\
Constant & 4.1693 & 12.964 \\
Male & 0.6765 & 4.532 \\
Black/Hispanic & -0.5793 & -7.049 \\
Age & 0.318 & 2.178 \\
Education & 0.0749 & 2.87 \\
Error variance & & \\
Std. dev. Shadow wage & 2.5543 & 39.176 \\
Std. dev. Market wage & 3.2322 & 39.085 \\
Correlation & 1.7867 & 4.857 \\
\hline \hline anependent variable is the natural log of the wage rate & \\
bcorrelation is $\rho=\exp (\delta) / 1+\exp (\delta)$ where $\delta$ is estimated & \\
&
\end{tabular}


Table 3: Maintenance Function Estimation

\begin{tabular}{|c|c|c|c|}
\hline \multirow{2}{*}{$\begin{array}{l}\text { Variable } \\
\text { Constant }\end{array}$} & \multicolumn{3}{|c|}{$\begin{array}{c}\text { Quadratic Model } \\
\text { Estimated coefficient } \\
\text { (Robust z-statistic) }\end{array}$} \\
\hline & $\begin{array}{l}115.42 \\
(32.20)\end{array}$ & $\begin{array}{l}59.76 \\
(6.05)\end{array}$ & $\begin{array}{l}60.24 \\
(8.19)\end{array}$ \\
\hline $\begin{array}{l}\text { Shadow wage/ personal services } \\
\text { price }\end{array}$ & $\begin{array}{l}-2.29 \\
(-4.24)\end{array}$ & $\begin{array}{l}-2.11 \\
(-4.49)\end{array}$ & $\begin{array}{l}-2.50 \\
(-7.51)\end{array}$ \\
\hline Respondent's labor income & & $\begin{array}{l}-1 \times 10^{-4} \\
(-4.66)\end{array}$ & $\begin{array}{c}-1.4 \times 10^{-4} \\
(-5.73)\end{array}$ \\
\hline Spouse, etc. in household & & $\begin{array}{l}27.11 \\
(4.86)\end{array}$ & $\begin{array}{l}41.30 \\
(8.68)\end{array}$ \\
\hline $\begin{array}{l}\text { Number of family members in } \\
\text { house }\end{array}$ & & $\begin{array}{l}12.49 \\
(8.32)\end{array}$ & $\begin{array}{l}10.13 \\
(8.77)\end{array}$ \\
\hline Age & & $\begin{array}{l}-0.153 \\
(-0.82)\end{array}$ & $\begin{array}{c}.056 \\
(0.38)\end{array}$ \\
\hline Work distribution in household & & $\begin{array}{c}2.81 \\
(1.00)\end{array}$ & $\begin{array}{l}4.98 \\
(2.31)\end{array}$ \\
\hline Flexibility in work hours & & $\begin{array}{c}8.50 \\
(1.41)\end{array}$ & $\begin{array}{l}12.37 \\
(2.61)\end{array}$ \\
\hline Completeness of response & & & $\begin{array}{c}0.37 \\
(14.68)\end{array}$ \\
\hline Choose more paid work & & & $\begin{array}{l}-31.68 \\
(-6.18)\end{array}$ \\
\hline Choose more housework & & & $\begin{array}{l}-43.49 \\
(-11.49)\end{array}$ \\
\hline Sigma & 55.24 & 44.97 & 33.97 \\
\hline Log Likelihood & -2104.82 & -1836.23 & -1718.66 \\
\hline \# of obs. & 1907 & 1719 & 1719 \\
\hline \# uncensored & 310 & 282 & 282 \\
\hline
\end{tabular}


Table 4: Sample Quantiles of Marginal Value of Time for Trips of Different Lengths (2003 dollars per hour)

\begin{tabular}{cccccc}
\hline \hline Quantile & Baseline & 2-hour trip & 4-hour trip & 6-hour trip & 8-hour trip \\
\hline $10 \%$ & 1.65 & 1.74 & 1.80 & 1.88 & 1.97 \\
$25 \%$ & 5.70 & 5.94 & 6.10 & 6.17 & 6.39 \\
$50 \%$ & 19.61 & 20.14 & 20.80 & 21.48 & 22.19 \\
$75 \%$ & 31.89 & 33.10 & 34.32 & 35.61 & 37.00 \\
$90 \%$ & 57.64 & 61.19 & 64.20 & 66.58 & 69.05 \\
\hline \hline
\end{tabular}

Table 5: Sample Averages for Total Value of Time for Trips of Different Lengths (2003 dollars per hour)

\begin{tabular}{|c|c|c|c|c|c|}
\hline & $\begin{array}{l}\text { One-Third } \\
\text { Wage Rate }\end{array}$ & Wage Rate & $\begin{array}{l}\text { Feather } \\
\text { and Shaw }\end{array}$ & PPS & $\begin{array}{c}\% \\
\text { Difference: } \\
\text { FS and PPS }\end{array}$ \\
\hline $\begin{array}{l}\text { Baseline Marginal } \\
2 \text { Hour Trip }\end{array}$ & 12.56 & 38.05 & 26.65 & 26.65 & 0.00 \\
\hline Mean Total & 25.11 & 76.10 & 53.30 & 54.51 & 2.27 \\
\hline $\begin{array}{l}\text { Mean Marginal } \\
4 \text { Hour Trip }\end{array}$ & 12.56 & 38.05 & 26.65 & 27.89 & 4.65 \\
\hline Mean Total & 50.23 & 152.20 & 106.60 & 111.57 & 4.66 \\
\hline $\begin{array}{l}\text { Mean Marginal } \\
6 \text { Hour Trip }\end{array}$ & 12.56 & 38.05 & 26.65 & 29.29 & 9.91 \\
\hline Mean Total & 75.34 & 228.30 & 159.90 & 171.54 & 7.28 \\
\hline $\begin{array}{l}\text { Mean Marginal } \\
8 \text { Hour Trip }\end{array}$ & 12.56 & 38.05 & 26.65 & 30.71 & 15.23 \\
\hline Mean Total & 100.45 & 304.40 & 213.20 & 234.37 & 9.93 \\
\hline Mean Marginal & 12.56 & 38.05 & 26.65 & 32.15 & 20.64 \\
\hline
\end{tabular}




\section{Appendix A: Excerpt from survey}

\section{Personal Assistance Services}

It is becoming more common to see firms that provide personal assistant services starting up. These types of businesses organize and perform many household tasks such as house cleaning, lawn care, food shopping, and a wide array of other tasks. Clients typically contract for a specific number of hours per week and specify the activities employees of the firm are to do. If transportation is needed for the tasks, it is provided by the firm and included in the number of hours that are purchased. Guarantees are made that the service is safe and reliable. It is not necessary for clients to be present when the tasks are performed. In spite of the growth in this industry, little is understood about how much of these services would be used.

If this personal assistance service was $\$ 5.50^{1}$ per hour used, would you purchase any time? yes no

If you answered yes, how much personal service time would you purchase in a typical week? Please check the relevant box or write in the value. (If no, skip to Part C, "Leisure Outings").

\begin{tabular}{|ccc|}
\hline $\begin{array}{c}\text { Hours Purchased In a } \\
\text { Typical Week }\end{array}$ & Total Weekly Cost & $\begin{array}{c}\text { Please Check the } \\
\text { Relevant Box }\end{array}$ \\
\hline 1 & $\$ 5.50 \times 1=\$ 5.50$ & $\square$ \\
2 & $\$ 5.50 \times 2=\$ 11$ & $\square$ \\
3 & $\$ 5.50 \times 3=\$ 16.50$ & $\square$ \\
4 & $\$ 5.50 \times 5=\$ 27.50$ & $\square$ \\
5 & $\square$ \\
If your purchase would be more than five hours, \\
please indicate how many:
\end{tabular}

The hours I would purchase would replace paid services I currently use for some household tasks.

$\square$ yes

$\square$ no

On average, how would you most likely use the time you saved by purchasing this service? (check most likely use)

$\square$ Use the time to work additional hours

Use the time for activities I enjoy

Use the time for other household tasks

\footnotetext{
${ }^{1}$ Prices of $\$ 5.50, \$ 8, \$ 10, \$ 20, \$ 30$, and $\$ 50$ were used on different versions of the survey.
} 


\section{Notes}

${ }^{1}$ Smith et al. [1983] also showed, using a related model, that the relationship between the value of time and the wage rate varied extensively. Larson and Shaikh [2001] suggest that both sets of results may well yield biased estimates because they failed to include a time budget variable in the site demand.

${ }^{2}$ Completely modeling the dynamic tradeoffs implied by inter-temporal choices might seem desirable. However, such a framework requires not only a record of the sequencing and duration of activities, but perhaps more importantly, an understanding of the constraints to the allocation of time over the course of a day, week, or month. At this time both data and modeling limitations preclude such a fully dynamic model. The sequential model presented here maintains the important insights while remaining empirically tractable.

${ }^{3}$ Multiple day vacations or recreation trips requiring an overnight stay are not included among these short run decisions, since their planning horizon is likely to be longer than we are focusing on in this model.

${ }^{4}$ We assume that individuals never choose to completely shift all maintenance from a period because the high initial marginal productivity of maintenance. This assumption seems to accord well with actual behavior and guarantees interior solutions.

5 This is consistent with Hamermesh's (2005) treatment of the role of household production for the timing of activities:

"Routine (selecting the same time for the same activity and repeating it at the same time over several periods) is productive, in that it enables the producer/consumer to mechanize decisions about when and how to engage in each activity, thus allowing her to produce/consume more of each commodity" (p.82, parenthetical description inserted).

Hamermesh also discusses the costs of shifting activities between periods to gain variety. His model suggests that variety contributes to utility, but routine behavior reduces the costs of the activity.

${ }^{6}$ Both Lagrange multipliers are functions of the parameters of the optimization problem. Holding the parameters constant we can describe the effects of the marginal product function for a given level of time allocated to maintenance on the opportunity cost of time implied by the framework.

${ }^{7}$ Since total maintenance over the time periods is predetermined as is the number of time periods, the average per period is predetermined. 
${ }^{8}$ In this empirical model we use $L$ to denote own maintenance labor to distinguish the amount of planned labor in the typical week from the actual amount of labor $t_{m}^{j}$, decided at the short time horizon.

${ }^{9}$ An alternative way to interpret this equation would be to divide both sides by the marginal product of own labor. The individual should equate the marginal cost of own production to the price for purchased maintenance services.

${ }^{10}$ At a conceptual level there are parallels between our structure and what Hall [2009] uses recently in a macro context. He finds the disparity between the value of time and the marginal product of labor can be reconciled through complementarities between consumption and labor. In our context it is the opportunity to adjust a discrepancy in the marginal product of labor for maintenance that allows measurement of the opportunity cost of time.

${ }^{11}$ This figure reflects adjustment for changes that were not captured with the cross check of tax records. These include household re-location, death, age limiting a designated respondent's ability to answer, and mail loss.

${ }^{12}$ We eliminated observations with a predicted shadow wage greater than $\$ 500$, those with reported own maintenance hours greater than 150 hours/week, and those who reported they would purchase more hypothetical hours of services than they reported actually doing themselves.

${ }^{13}$ Response rates in the studies these authors considered ranged from 4 percent to 70 percent. A second study by Keeter et al. (2000) compared a "standard" and "rigorous" survey using identical questionnaires. The standard realized a response rate of 36 percent and the rigorous 60.6. The authors considered 96 comparisons, no difference exceeded 9 percentage points and the average difference was 2 points.

${ }^{14}$ Details of the estimation controlling for non-response are available in an appendix available from the authors.

${ }^{15}$ In the questions preceding the time allocation questions, to orient respondents to time related choices, the survey also asked about a variety of time-saving market products and services they may have used recently.

16 Each respondent was offered a specific price that was randomly selected from six prices. The six prices are given in the Appendix.

${ }^{17}$ The complete sections of the survey on time use and time-saving activities are available from the authors on request.

${ }^{18}$ Some of the respondents indicated that they were using hired assistance already for household tasks. For those who indicated that the hypothetical services we offered would be substituted for 
the services they already used, we added their own household time and the hired time before subtracting their purchase of the offered services. For those who said the offered services would not be substituted for the hired services they were currently using, we used the current own time and subtracted their purchase of the offered services.

${ }^{19}$ The results for the log form are available from the authors.

${ }^{20}$ Recall that the dependent variable is the combined hours of maintenance in the household and not hours done by the respondent.

${ }^{21}$ See Kahneman et al. (2004) for related discussion of this issue.

${ }^{22}$ Frazis and Stewart observe that the opportunity cost approach to valuing labor time has conceptual and practical difficulties. They highlight that: "On a conceptual level, the implicit assumption that hours of paid work are freely variable at the margin may not hold; workers, at least in the short run, may have little choice in their working hours. Perhaps more importantly, the opportunity cost approach assumes that people who are highly productive in market work are just as productive doing household work. It is hard to imagine that lawyers are five times more productive building a deck than a carpenter" (p.14). 


\section{Survey Sections on Time Use and Values \\ (to be available from the authors)}

\section{B. Time Use and Time Saving Activities}

6. Now we would like you to think about your typical weekly schedule and what you and your spouse/partner do with your time on average. In a typical week, about how much time do you and your spouse/partner (if relevant) spend on each of the following activities? For some categories you may hire paid help. If so, the third column asks how many hours in a typical week you pay someone to help with some of these activities. Finally, if you feel you are able to freely choose the amount of time you spend each week on an activity please check the associated line in the last column.

\begin{tabular}{|c|c|c|c|c|}
\hline Activities/Tasks & You & Spouse/Partner & $\underline{\text { Paid Help }}$ & Freely Choos \\
\hline commuting to work & hrs & hrs & & \\
\hline paid work (primary job) & hrs & $\ldots$ hrs & & 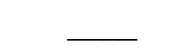 \\
\hline second job (if relevant) & hrs & $\ldots$ hrs & & ـ \\
\hline $\begin{array}{l}\text { household activities } \\
\text { (e.g. cleaning, cooking, etc.) }\end{array}$ & hrs & hrs & _hrs & \\
\hline yard work / gardening & hrs & hrs & _ hrs & \\
\hline activities related to your children & hrs & hrs & hrs & \\
\hline reading newspapers, books, magazines & hrs & hrs & & \\
\hline $\begin{array}{l}\text { shopping for routine needs and } \\
\text { running errands (e.g. food) }\end{array}$ & hrs & hrs & hrs & \\
\hline watching TV/video & hrs & hrs & & \\
\hline family related social activities & hrs & $\ldots$ hrs & & - \\
\hline $\begin{array}{l}\text { outdoor leisure activities away } \\
\text { from your house (e.g. walking, } \\
\text { fishing, boating, riding a bike, etc.) }\end{array}$ & hrs & hrs & & \\
\hline $\begin{array}{l}\text { time on the computer/internet } \\
\text { away from work }\end{array}$ & hrs & hrs & & \\
\hline entertainment away from home & hrs & hrs & & \\
\hline church activities & hrs & hrs & & - \\
\hline exercise/workouts & hrs & hrs & & \\
\hline
\end{tabular}


5. Is the time you have available for leisure flexible in terms of both the day of the week and the time of day? (Choose one)

\footnotetext{
flexible - can use time for leisure activities anytime of the day or week limited by work schedule limited by non-work commitments (e.g., volunteer, children's activities, etc.) limited by both work and non-work commitments
}

6. If you had the opportunity to work fewer hours and receive less income or work more hours and receive more income with the rate of pay in each case consistent with your current earnings (on approximately a per hour basis), would you change your hours? Please check the appropriate response.

I would work more hours and receive more income

I would work less hours and receive less income

I would not change my working time 
9. There are many ways people try to save time. We buy time saving appliances, shop with catalogs or online, hire others to help with activities around the house, etc.

Please check any of the following types of time saving appliances or services that you have purchased or used because you wanted to save time.

\footnotetext{
$\square$ shop with catalog or on an internet web site

$\square$ used on-line banking

used an ATM

$\square$ used a home cleaning service

$\square$ used a lawn service

$\square$ used clothes cleaning services

$\square$ used a drive-up pharmacy

$\square$ ate at a fast food restaurant

purchased frozen dinners or ready made meals

$\square$ used periodic babysitting services

$\square$ had daily childcare service

$\square$ used a mobile phone regularly

$\square$ used a food shopping service

$\square$ purchased delivery pizza

used dog walking service
} 


\section{Personal Assistance Services}

It is becoming more common to see firms that provide personal assistant services starting up. These types of businesses organize and perform many household tasks such as house cleaning, lawn care, food shopping, and a wide array of other tasks. Clients typically contract for a specific number of hours per week and specify the activities employees of the firm are to do. If transportation is needed for the tasks, it is provided by the firm and included in the number of hours that are purchased. Guarantees are made that the service is safe and reliable. It is not necessary for clients to be present when the tasks are performed. In spite of the growth in this industry, little is understood about how much of these services would be used.

If this personal assistance service was $\$ 5.50$ per hour used, would you purchase any time?

$$
\text { yes }
$$$$
\text { no }
$$

If you answered yes, how much personal service time would you purchase in a typical week? Please check the relevant box or write in the value. (If no, skip to Part C, "Leisure Outings").

\begin{tabular}{|ccc|}
\hline $\begin{array}{c}\text { Hours Purchased In a } \\
\text { Typical Week }\end{array}$ & Total Weekly Cost & $\begin{array}{c}\text { Please Check the } \\
\text { Relevant Box }\end{array}$ \\
\hline 1 & $\$ 5.50 \times 1=\$ 5.50$ & $\square$ \\
2 & $\$ 5.50 \times 2=\$ 11$ & $\square$ \\
3 & $\$ 5.50 \times 3=\$ 16.50 \times 4=\$ 22$ & $\square$ \\
4 & $\$ 5.50 \times 5=\$ 27.50$ & $\square$ \\
5 & \\
If your purchase would be more than five hours, \\
please indicate how many:
\end{tabular}

The hours I would purchase would replace paid services I currently use for some household tasks.

$$
\begin{aligned}
& \square \text { yes } \\
& \square \text { no }
\end{aligned}
$$

On average, how would you most likely use the time you saved by purchasing this service? (check most likely use)

$\square$ Use the time to work additional hours

Use the time for activities I enjoy

Use the time for other household tasks 